\title{
Treatment of congenital epulis (granular cell tumour) with excision and gingivoperiosteoplasty
}

\author{
Kailash Narasimhan MD ${ }^{1}$, Jugpal S Arneja MD FRCSC ${ }^{2}$, Rajah Rabah MD ${ }^{3}$
}

\begin{abstract}
K Narasimhan, JS Arneja, R Rabah. Treatment of congenital epulis (granular cell tumour) with excision and gingivoperiosteoplasty. Can J Plast Surg 2007;15(4):215-218.

Congenital epulis, or granular cell tumour, is a rare, benign intraoral tumour present on the mucosa of the alveolar ridge, with the potential to interfere with respiration and feeding. Treatment involves surgical excision, and recurrences are rare. The management of the alveolar deficiency associated with this tumour has not previously been addressed. In the present report, a patient with a typical epulis, treated surgically with excision and extrapolation of Millard's gingivoperiosteoplasty technique to reconstruct the associated alveolar defect with restoration of alveolar ridge continuity, is presented. The differential diagnosis and complications of this tumour are discussed.
\end{abstract}

Key Words: Epulis; Gingivoperiosteoplasty

\section{CASE PRESENTATION}

A five-day-old, full-term female infant presented with a premaxillary mass noted initially at time of spontaneous vaginal delivery. The mother's pregnancy was uncomplicated and prenatal ultrasounds revealed no structural abnormalities. The patient was breast- and bottle-fed without difficulty, weighed $4186 \mathrm{~g}$ on initial presentation and had no respiratory difficulties. The mother thought the patient could intermittently make adequate suction for feeding. Reviews of the infant's systems and family history were unremarkable.

On examination, the patient was not in respiratory distress and appeared to have age-appropriate mental and physical development. On craniofacial examination, her lip appeared to

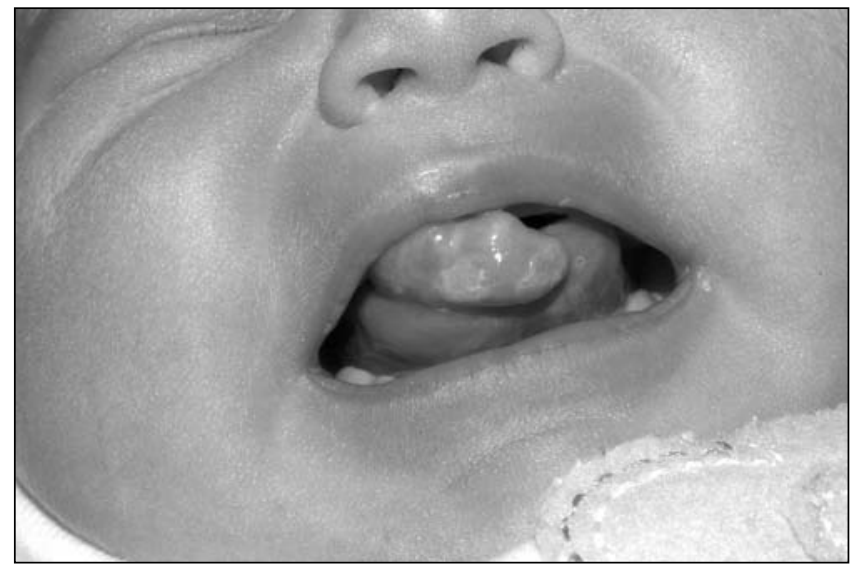

Figure 1) Initial presentation of alveolar ridge tumour

\section{Traitement de l'épulis congénitale (tumeur à cellules granuleuses) par excision et gingivopériostéoplastie}

L'épulis congénitale, ou tumeur à cellules granuleuses, est une tumeur intra-orale bénigne rare que l'on observe sur la muqueuse de la crête alvéolaire et qui peut nuire à la respiration et à l'alimentation. Le traitement repose sur une excision chirurgicale et les récurrences sont rares. La prise en charge du déficit alvéolaire associé à cette tumeur n'a pas encore été abordée. Le présent rapport fait donc état d'une patiente atteinte d'une épulis typique, traitée chirurgicalement par excision et extrapolation de la technique de gingivopériostéoplastie de Millard afin de reconstruire le déficit alvéolaire avec restauration de la continuité de la crête alvéolaire. Le diagnostic différentiel et les complications de cette tumeur sont décrits ici.

be well-formed; however, along the right premaxillary region, a $2.2 \mathrm{~cm} \times 1.5 \mathrm{~cm}$ mass was present (Figure 1). No overt cleft of the primary palate was noticed other than a small, incomplete notch just posterior to the mass. The secondary palate was intact with no evidence of overt or submucous cleft palate. The remainder of the physical examination, including upper airway and chest, abdomen and neuromuscular, was unremarkable.

Facial radiographs showed a right alveolar notch and premaxillary mass, with no dental elements present within the mass. Given the clinical findings, the patient was taken to the operating room for excision with gingivoperiosteoplasty (GPP) reconstuction of the alveolar defect (Figure 2). A $1 \mathrm{~cm} \times 1.8 \mathrm{~cm}$,

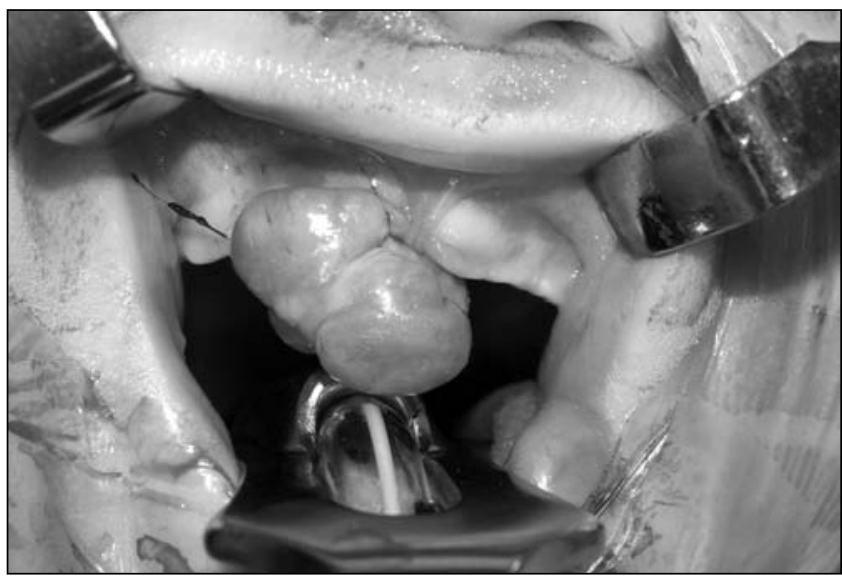

Figure 2) Tumour overlying the right alveolar ridge and extending toward the buccal surface of the lip

${ }^{1}$ Department of Otolaryngology, Wayne State University; ${ }^{2}$ Section of Plastic Surgery, Wayne State University and Children's Hospital of Michigan; ${ }^{3}$ Department of Pathology, Children's Hospital of Michigan, Detroit, Michigan, USA

Correspondence and reprints: Dr Jugpal S Arneja, Children's Hospital of Michigan, 3901 Beaubien Boulevard, Detroit, Michigan 48201, USA.

Telephone 313-745-0247, fax 313-993-8783, e-mail arneja@med.wayne.edu 


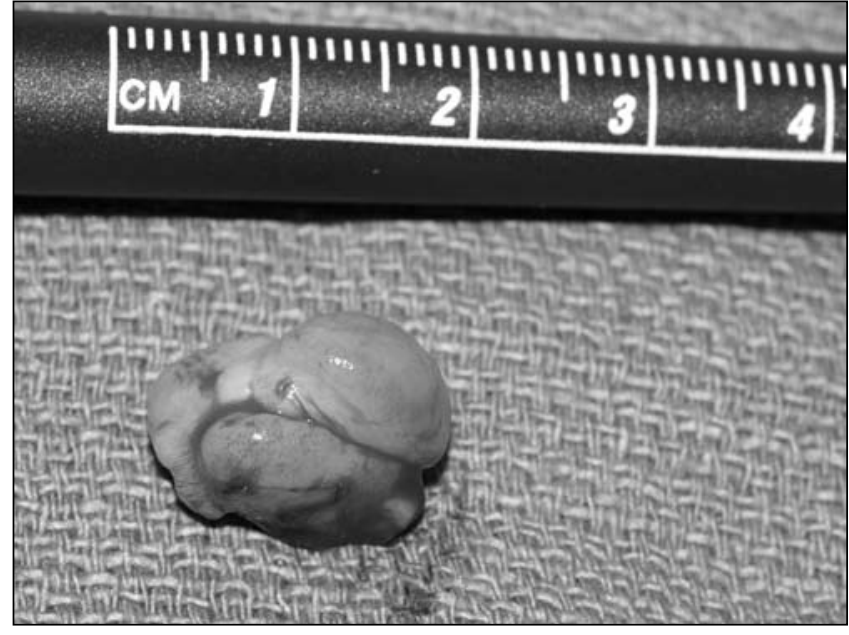

Figure 3) Rubbery, pink-tan tumour measuring $1 \mathrm{~cm} \times 1.8 \mathrm{~cm}$ postexcision

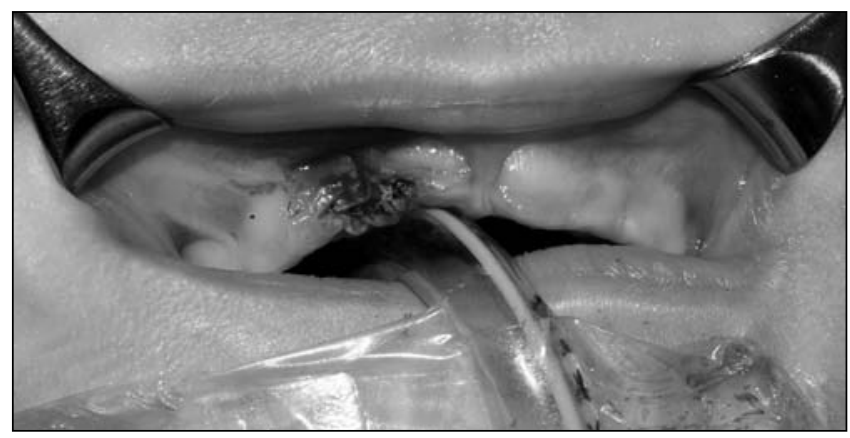

Figure 4) Right alveolar ridge after gingivoperiosteal flaps were raised laterally and advanced medially to cover the defect with closure with 5-0 vicryl horizontal mattress sutures

pink-tan, rubbery mass of tissue was excised from the right alveolar ridge (Figure 3). The resulting defect was a notch in the right premaxilla. Subsequently, gingivoperiosteal flaps were elevated laterally to the defect and advanced medially. 5-0 vicryl horizontal mattress sutures were used to repair the defect (Figure 4).

Postoperatively, the patient had no signs of respiratory distress or feeding difficulty, and she demonstrated age-appropriate weight gain. The intraoral alveolar wound healed without complication and no signs of infection or mass recurrence were noted. Gross pathological review of the excised mass demonstrated polypoid tissue covered by nonkeratinizing squamous epithelium. Histopathology revealed focal ulceration with underlying stroma demonstrating large sheets of closely packed, polygonal cells with round, regular nuclei and inconspicuous nucleoli, and abundant granular cytoplasm (Figure 5), consistent with a diagnosis of epulis, or granular cell tumour (GCT). One year postoperatively, the patient had a functionally and developmentally normal alveolar ridge without tumour recurrence (Figure $6 \mathrm{~A}$ and $6 \mathrm{~B}$ ), and at 18 months postoperatively a developmentally normal dental maxillary arch was present (Figure 6C).

\section{DISCUSSION}

Epulis is not a new or recent entity to be discovered; however, our decision to perform a GPP represents a novel approach in

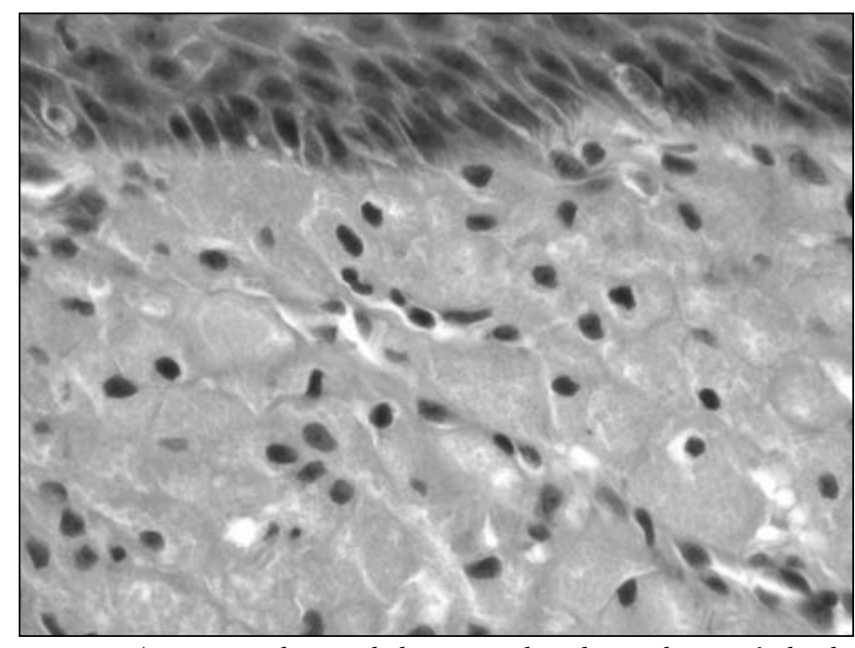

Figure 5) Tumour histopathology revealing large sheets of closely packed polygonal cells with prominent membranes beneath the mucosa. Round regular nuclei with inconspicuous nucleoli and abundant granular cytoplasm was present

the surgical management of the defect associated with this entity.

Congenital epulis, more recently renamed GCT of the newborn, describes a very rare, benign intraoral tumour present in the mucosa of the alveolar ridge. Grossly, the typical appearance is smooth, pedunculated and pink. Epulis is distinguished from other oral soft tissue tumours by its maxillary or mandibular alveolar location (3:1) usually around the canine incisor, its female (8:1) predominance and its solitary nature (1). Based on its size, documented to be up to $9 \mathrm{~cm}$, this tumour can complicate feeding and respiration (2). Polyhydramnios has also been noted due to a blockage of the oral cavity and an inability to swallow (3). One report documented absent development of the upper left incisor; however, tooth development at the site of the lesion was normal post-GPP in our patient (Figure 6C) (2).

There are several theories on the origin of congenital epulis, because its histogenesis remains controversial. The presumed cellular origin is odontogenic, deriving from epithelial cells of the dental lamina. Occasionally, nests of odontogenic epithelium are seen under the microscope. Other possible derivations include fibroblasts, histiocytes, myocytes and neural crest cells. Studies on neurofibromatosis have been used to support both fibroblastic and neural derivations (4). However, the currently accepted theory is that epulis represents a reactive entity, and recent immunohistochemical staining and ultrastructural examination favour myofibroblasts as the cell of origin. Indeed, oral pathologists have found cells of congenital GCT to have contractile fibres with the ability to produce collagen. These cells most likely represent mesenchymal elements that express pericyte or myofibroblastic features, and undergo cytoplasmic autophagocytosis later on $(4,5)$. As in our case, electron microscopy typically demonstrates gingival stromal elements derived from either histiocytes, fibroblasts or a common stem cell progenitor.

Clinically, a lack of growth, documented spontaneous regression and a failure to recur after resection further supports the reactive theory $(6,7)$. Female preponderance and in utero 
growth have given support to a theory of uterine hormones as a stimulus for epulis. However estrogen receptor studies have been shown to be negative $(6,8,9)$.

In addition to congenital epulis, an adult form of GCT also exists. While the congenital form affects neonatal gums, the adult form most commonly affects the tongue and subcutaneous regions. Adult GCT has also been described in the soft palate, lips, floor of the mouth and upper airway structures (10). It is thought to be derived from Schwann cells (10). However interestingly, both congenital and adult GCT are histologically indistinguishable.

The main differential diagnosis for congenital GCT is the more common myoblastoma. Myoblastoma is derived from Schwann cells of the nerve sheath, occurs in deeper tissues and has pseudoepitheliomatous hyperplasia. It has a more widespread anatomical distribution including the gastrointestinal submucosa, and occurs at any age. Myoblastomas also have an $8 \%$ recurrence rate, stain for S-100 and can undergo malignant degeneration. Other differential diagnoses for congenital GCT include lymphoma, fibroma, rhabdomyoma, granuloma, Epstein's pearls, hemangioma and heterotopic gastrointestinal cyst $(1,11)$.

Recommended management for epulis is surgical excision, although some opt to wait for spontaneous regression if the mass is small and is not interfering with respiration or feeding. Past literature has described no recurrence following even incomplete excision (1). However, these masses can leave a notch in the alveolus that may result in an incomplete dental arch. Past case reports on epulis do not further address the problem of an alveolar cleft following excision.

In our case, we chose to undermine and advance gingivoperiosteal flaps, and suture them over the bony defect, thus extrapolating the techniques used by Millard and Latham (12) for cleft alveolar management. This approach applies the premise that correct dental development requires a complete alveolar arch. Our patient's mass was adherent to the alveolar ridge and affected alveolar continuity. Some authors differ on the exact timing of GPP. Millard suggests initial GPP along with lip repair.

However, as long as GPP is performed early, it can restore physiological continuity across the premaxilla and allow osteogenic hematoma formation between the anterior maxillary cleft. It is thought that union of the mucoperiosteum across an alveolar and anterior hard palate defect creates a periosteal tunnel conducive to bone formation and normal tooth eruption along the cleft region (12). Because the infant's periosteum, specifically the inner layer, has a high osteogenic potential, this technique makes biochemical logic. Success of the procedure relies on the integrity and vascularity of the periosteum. Therefore, meticulous surgical technique, including wide subperiosteal undermining, is critical. In our patient, using a periosteal elevator and scalpel, the gingivoperiosteal flaps were elevated off the maxilla and these flaps were carefully advanced and sutured in continuity to each other, thereby obliterating the defect (13).

\section{CONCLUSION}

We present the excision of a typical-appearing epulis, or GCT, with a reconstructive modality typically used for alveolar clefts. Primary alveolar reconstruction by GPP achieves proper alignment and promotes normal tooth development (14). Although rare, for defects created by congenital pathology in
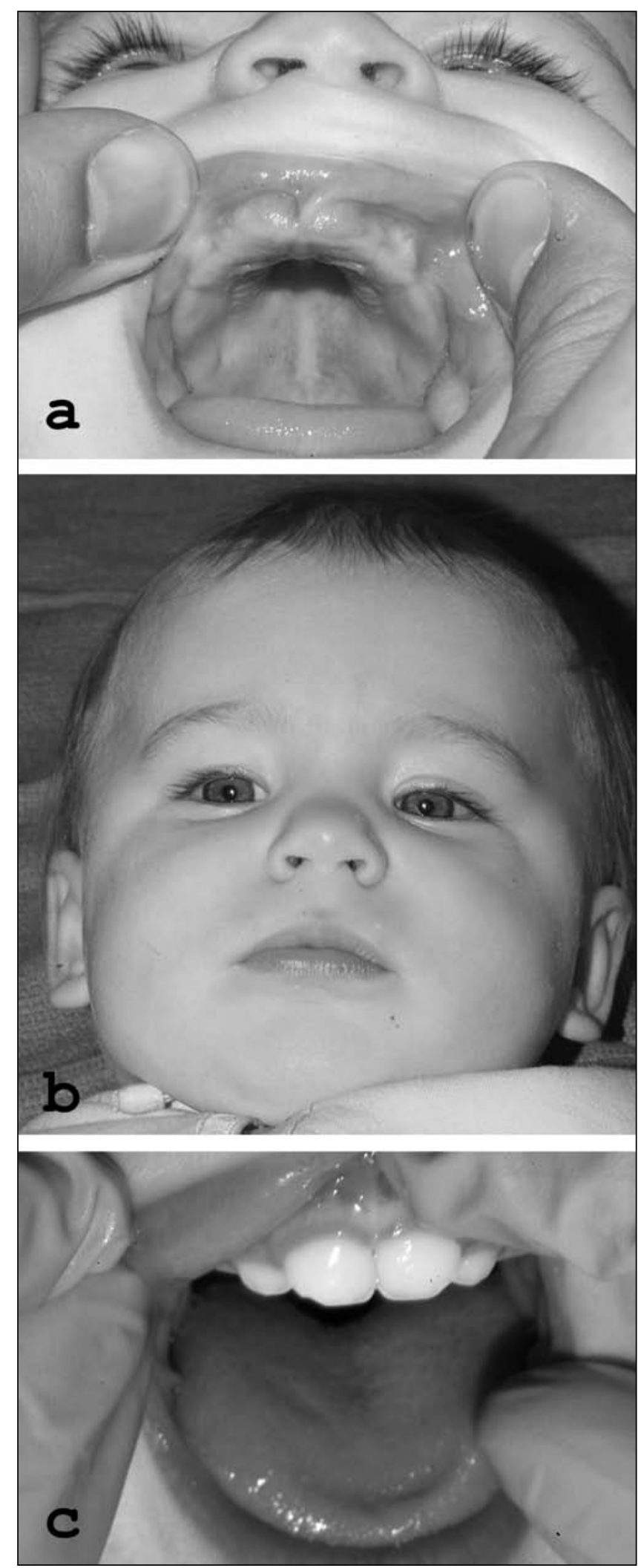

Figure 6) A and B One-year postoperative result suggestive of a functionally and developmentally normal alveolar ridge without tumour recurrence. C Follow-up at 18 months showing normal tooth development

the alveolar ridge, GPP should be considered for reconstruction. 


\section{REFERENCES}

1. Eppley BL, Sadove AM, Campbell A. Obstructive congenital epulis in a newborn. Ann Plast Surg 1991;27:152-5.

2. Blair AE, Edwards DM. Congenital epulis of the newborn. Oral Surg Oral Med Oral Pathol 1977;43:687-91.

3. Lopez de Lacalle JM, Aguirre I, Irizabal JC, Nogues A. Congenital epulis: Prenatal diagnosis by ultrasound. Pediatr Radiol 2001;31:453-54.

4. Hoyme HE, Musgrave SD Jr, Browne AF, Clemmons JJ. Congenital oral tumor associated with neurofibromatosis detected by prenatal ultrasound. Clin Pediatr (Phila) 1987;26:372-4.

5. Damm DD, Cibull ML, Geissler RH, Neville BW, Bowden CM, Lehmann JE. Investigation into the histogenesis of congenital epulis of the newborn. Oral Surg Oral Med Oral Pathol 1993;76:205-12.

6. Fuhr AH, Krogh PH. Congenital epulis of the newborn: Centennial review of the literature and a report of a case. J Oral Surg 1972;30:30-5.

7. O'Brian FV, Pielou WD. Congenital epulis: Its natural history. Arch Dis Child 1971;46:559-60.
8. Olson JL, Marcus JR, Zuker RM. Congenital epulis. J Craniofac Surg 2005;16:161-4.

9. Lack EE, Perez-Atayde AR, McGill TJ, Vawter GF. Gingival granular cell tumor of the newborn (congenital "epulis"): Ultrastructural observations relating to histogenesis. Hum Pathol 1982;18:686-9.

10. Kanotra S, Kanotra SP, Paul J. Congenital epulis. J Laryngol Otol 2006;120:148-50.

11. Takahashi H, Fujita S, Satoh H, Okabe H. Immunohistochemical study of congenital granular cell tumor (congenital epulis). J Oral Pathol Med 1990;19:492-6.

12. Millard DR Jr, Latham RA. Improved primary surgical and dental treatment of clefts. Plast Reconstr Surg 1990;86:856-71.

13. Smith WP, Markus AF, Delaire J. Primary closure of the cleft alveolus: a functional approach. Br J Oral Maxillofac Surg 1995;33:156-65.

14. Lukash FN, Schwartz M, Grauer S, Tuminelli F. Dynamic cleft maxillary orthopedics and periosteoplasty: Benefit or detriment? Ann Plast Surg 1998;40:321-6. 